\title{
Business Legitimacy, Agricultural Biodiversity and Environmental Ethics: Insights from Sustainable Bakeries
}

\author{
Riccardo Torelli \\ Università Cattolica del Sacro Cuore - Department of Economic and Social Sciences \\ Via Emilia Parmense 84 - 29122 Piacenza (Italy) \\ riccardo.torelli2@unicatt.it
}

\section{Federica Balluchi}

University of Parma - Department of Economics and Management

\begin{abstract}
The relationship between biodiversity and ethics is complex and concern the broader environmental ethics. In the agricultural industry, these issues are fundamental and, in the context of agro-biodiversity, bread production activity plays a primary role. Artisanal bread and its derivatives represent basic food products and a short supply chain, with only one intermediate step between the producer of the raw material (flour) and the consumer, represented by bakery. Furthermore, bakery industry is characterized by different needs, motivations, evaluations and ethical/moral values, as well as philosophical considerations towards nature, of producers and consumers. Through a multiple case study on four specific companies of the interesting and relevant natural and sustainable bakery industry, our aim is to understand what are the motivations and ethical-moral drives behind specific ideological and operational choices that have an impact on nature and its biodiversity. It is also intended to investigate how the different ethical-philosophical approaches to nature lead to economic and management choices that are also very distant from each other and have different impacts on the protection and promotion of agricultural biodiversity. This study has allowed to place the positions and choices of some entrepreneurs and artisans in the different ethical approaches to nature and therefore to biodiversity. It was also possible to highlight how the different behaviours of consumers and producers arise from the ethical conceptions through which they look at reality and the consequences of their choices on production and sales activities.
\end{abstract}

Keywords: Biodiversity; Agro-Biodiversity; Ethics; Environment; Bakery; Crops; Sustainability. 


\section{Introduction}

Biodiversity and ethics are two very related concepts and concern the broader environmental ethics field. The relationship between the two concepts is linked to the multifaceted conceptual nature of biodiversity and, at the same time, to the debate on rights and value of life of animal and plant beings. For this reason, the study of the ethical perspective of biodiversity cannot disregard philosophical thinking of ancient and current scholars. The different ethical approaches to nature and, therefore, to biodiversity, lead to a variety of ethical: from anthropocentrism to cosmocentrism.

The different visions of the importance of nature in relation to humans certainly concern the agricultural production industry in which the issue of biodiversity conservation is fundamental. In fact, agro-biodiversity is the sub-category of biodiversity most at risk and most relevant in European continent (Negri, 2005) and it has still not very deepened and considered (Lanka et al., 2017).

In the context of agro-biodiversity, bread production activity plays a non-secondary role. Indeed, bread and its derivatives represent basic food products and a short supply chain, with only one intermediate step between the producer of the raw material (flour) and the consumer, represents bakery industry. Furthermore, bakery industry is characterized by different needs, motivations, evaluations and ethical/moral, as well as philosophical considerations towards nature, of producers and consumers meet/conflict.

Starting with these brief considerations, through a multiple case study on four specific firms of the interesting and relevant natural and sustainable bakery industry, our aim is to understand what are the motivations and ethical-moral drives behind specific ideological and operational choices that have an impact on nature and its biodiversity. It is also intended to investigate how the different ethical-philosophical approaches to nature lead to economic and management choices that are also very distant from each other and have different impacts on the protection and promotion of agricultural biodiversity.

The chapter is composed by six main sections: the first paragraph deepens the link between biodiversity and ethics. In the second, we propose a brief analysis of the contributions in the various fields of study that, specifically, deal with the relationship between biodiversity and ethics; we then propose some reflections on the relationship between ethical duties and economic behaviours. After clarifying the methodology behind our study, we discuss evidences from case studies. We conclude the chapter with some final considerations.

\section{Biodiversity and ethical approaches}

Biodiversity is defined by "the number and types of plants and animals that exist in a particular 
area or in the world generally" ${ }^{1}$. In this sense, biodiversity, and its conservation, is fundamental for primary resources of the human being (e.g. food production, drugs, clothes), but also for the balance of natural habitats and ecosystems (e.g. climate stabilization, pollination, soil erosion) (Jones, 2003; Jones \& Solomon, 2013). On the other side, ethics can be defined as "moral principles that govern a person's behaviour or the conducting of an activity" or "the study of what is morally right and wrong, or a set of beliefs about what is morally right and wrong" 2 . Ethics refers also to "general beliefs, attitudes or standards that guide customary behaviour" (des Jardins, 1997: 16). It is clear, therefore, that biodiversity and ethics are closely interrelated issues and concern the broader and more philosophical concept of environmental ethics (e.g.: Callicott, 2002; Minteer \& Collins, 2005; Nelson, 2002; Norton, 1984; Rolston, 1988; Taylor, 1986; Tilman, 2000).

The complexity of the relationship between biodiversity and ethics is linked, on the one hand, to the multifaceted conceptual nature of biodiversity and, on the other, to the broad debate on the issue of the rights and value of life of animal and plant beings. For this reason, the study of the ethical perspective of biodiversity cannot disregard the thinking of philosophers such as Aristotle and Kant; these approaches must, however, be integrated with the approaches and visions of more current scholars. The result of this analysis is the identification of different ethical approaches to nature and, therefore, to biodiversity, ranging from anthropocentrism to cosmocentrism.

A useful document for the understanding of the ethical aspects of biodiversity is the UNESCO report published in 2011 as part of the larger project "Ethics and Climate Change in Asia and the Pacific" (ECCAP) and drafted on the occasion of the International Year of Biodiversity (2010) and the International Year of Forests (2011). In particular, the aim of the project was to stimulate a discussion on environmental ethics that would lead to tangible interdisciplinary results useful to support long-term national and international policies. More specifically, "the project aim to increase awareness and discussion of the complex ethical dilemmas related to energy and the environment, and to identify scientific data, and available ethical frameworks of values and principles for policy options that have proven useful in facing the challenges in certain communities and countries" (UNESCO, 2011: vi). After having deepened the concept of biodiversity ("the variability among living organisms from all sources including, inter alia, terrestrial, marine, and other aquatic ecosystems and the ecological complexes of which they are a part; this includes diversity within species and of ecosystems". UNESCO, 2011: 2), its components (genetic, microbial and ecosystem diversity) and the issues related to its measurement, the Report provides an interesting and in-depth analysis of the ethical implications with respect to biodiversity proposing, in a philosophical and multiple ethical approaches, "the ways in which ethics and biodiversity are interconnected and how the

\footnotetext{
${ }^{1}$ Cambridge English Dictionary (2019).

${ }^{2}$ Cambridge English Dictionary (2019).
} 
implications of decision manifest themselves based on the categorical differences between the approaches that are discussed" (UNESCO, 2011: 9).

The main philosophical approaches to biodiversity are anthropocentrism, biocentrism, ecocentrism, deep ecology and cosmocentrism; in the following, these are analysed without pretension of exhausting the subject also in the light of the necessary skills that escape our field of study.

Anthropocentrism is a tendency (of religions, theories or thoughts) that sees human as the most important being in the universe, therefore of every animal and vegetable being (Brian, 1984). This approach is at the basis of Aristotelian philosophy, which provides for a hierarchical priority of human over non-human beings; in other words, the animal and plant worlds assume importance as instrumental to human's well-being. In this approach, therefore, the natural environment and, therefore, biodiversity, assumes no importance except as useful (instrumental) with respect to human beings. Still within the philosophy of anthropocentrism, a less extreme vision is that expressed by Kant (1963); according to the philosopher, the treatment of non-humans must in any case be ethical at least for the effects on the morality of the man who makes instrumental use of them for his well-being. In this perspective, there is no explicit hierarchical position of human being in relation to animals, but it is stated that it is immoral to treat animals in such a way as to have negative effects on human morality. Therefore, in this view, human is in any case given priority over animals that have an instrumental value over the former. In other words, the protection of biodiversity is not an end in itself, but only if it is useful to humans (Kant, 1963).

Another approach is biocentrism according to which there are no hierarchical differences between beings in the universe and human is only one of them (Schweitzer, 1923). In this view all beings have an intrinsic value and human, by his work, is called to respect all other forms of life, non-human and natural (for more on the concept of intrinsic value in environmental ethics see: Callicot, 2002; Norton, 2000; Rolston, 1994; Russow, 2002). This need for respect is typical of biocentric egalitarianism, according to which all living beings are worthy of the same respect and this respect for nature means, among other things, the integrity of natural ecosystems (Taylor, 1981 and 1986)

In contrast to the two previous approaches is the ecocentrism according to which man must work with the objective of preserving ecosystems and living species in a sustainable development perspective; the ecosphere and biosphere play a central role in this perspective (Leopold, 1949). Basically, the philosophy of ecocentrism supports the importance of the value of a unitary "living complex" compared to that of the individual components of that complex: human, non-human beings and plants. In this regard, UNESCO Report: "While both anthropocentric and biocentric approaches represent the value of the beings within the life bearing matrix, the ecocentric approach represents the value of the matrix in sustaining the beings" (UNESCO, 2011: 14). 
In the same direction but with an ecological approach is deep ecology. According to this philosophy or, better, movement, first introduced in the 1970s by the philosopher Arne Naess, all living beings (human and non-human, vegetable and animal) have an intrinsic value that is also realized by the diversity and richness of the various forms of life. From this point of view, the human work of cannot threaten such diversity, except for reasons related to vital needs (Naess, 1973. For further information see: Devall \& Sessions, 1985; Tobias, 1985). Unlike anthropocentrism, biocentrism and ecocentrism, the theorization of deep ecology provides principles that are translated into real imperatives not present in purely philosophical approaches.

A final philosophical approach to environmental ethics is cosmocentrism. According to this approach, the value system is centred on the cosmos as a whole and the planet has a supreme value. Consideration of this approach, however, is particularly difficult because of its overwhelming effect on man.

\section{Biodiversity and ethics: theoretical background}

The relationship between biodiversity and ethics has been analysed from different perspectives ranging from philosophy to religion, from law to economics and to accounting. Without pretending to be exhaustive, in this paragraph we propose a brief description of some contributions whose object is specifically the analysis of the relationship between biodiversity and ethics.

From a philosophical point of view, the concept of biodiversity has recently been analysed examining the issues related to its conservation and the consequent regulatory implications (Mathews, 2016). From this perspective, the normative objective of biodiversity conservation is to ensure the survival of species and not "the abundance of species populations". In summary, however, preserving biodiversity means adapting it to the needs of human development in an anthropocentric ethic. In the light of this position, it is proposed "as an alternative basis for conservation policy, an ethic of bio-proportionality". In accordance with this principle, the goal "would be to optimize the populations of all species, relative only to the internal constraints imposed by the checks and balances inherent in ecosystems" (Mathews, 2016: 146).

In the field of theological studies, an interesting perspective of biodiversity analysis is proposed through the thought of Thomas Aquinas. In particular, proposing a way of approaching the traditional (human-concerned) doctrines with a view to their environmental virtue, the author gives a careful look at the way that salvation works that can be helpful to con-temporary problems in environmental theory (Jenkins, 2003). The motivation for such a deepening is rooted in the accusations that Christianity is anthropocentric and has contributed to the environmental crisis. The relationship between religion, ethics and biodiversity is deepened with an interdisciplinary perspective in Hamilton (1993); the volume, which includes the papers presented at the symposium of the XVII Pacific Science Congress held in Honolulu (Hawaii) 
in 1991, is based on the belief that non-biological aspects (religious and philosophical, for example) are at the basis of attitudes towards the conservation of biodiversity.

In the economic and managerial field, there are several points of reflection on the relationship between ethics and biodiversity. Spash et al. (2009), for example, apply a contingent valuation method introducing factors from social psychology to test the standard economic model of human behaviour, while also addressing ethical motives which are excluded by standard economic models. The model contrasts standard economic variables with ethical and behavioural psychology variables to reveal the underlying reasons for the willingness to make an economic sacrifice for the conservation of biodiversity. McEwan et al. (2014), using the case study methodology, offers an analysis of how expectations regarding the use of advanced technologies and, more generally, knowledge influence the debate on sustainability, biodiversity conservation and the ethics of economic choices. In other words, the authors "are interested in the politics of expectation that surround the use of technology, how the shift towards technology influences debates about sustainability in specific places, and how this shapes perspectives on what is ethical in such places" (McEwan et al., 2014: 206). After analysing the problems concerning the evaluation of the influence of psychological factors of an ethical-social nature on human behaviour, Butkus (2015) believes that the production activities of the pharmaceutical sector are no longer able to produce sufficient medicines to fight infections, cancers and viruses. In this perspective, author states that biodiversity is an essential condition of natural sources to replace the shortage of medicines. Therefore, failure to conserve biodiversity could threaten the treatment of diseases for current and future populations. Hence the ethical motivation for biodiversity conservation within a framework of preserving overall stability of the surrounding ecosystem. Such an approach based on the principles of sustainable biodiversity should be married to international and economic policy and the benefits derived from the latter; "should appeal to the egoist as much as the altruistthe strength of the relationship between preserving biodiversity and our ability to meet health challenges has benefits to both self and others" (Butkus, 2015: 9). Namkoong (1991) analyses the relationship between biodiversity and ethics within the broader issue of forest management. The author's starting point is to distinguish the subjects to be dealt from the objects to be managed: the subjects have an intrinsic value and must be protected, the objects have an instrumental value and must be managed. The ethical aspect lies in identifying which "organisms have inherent values, what moral obligations are owed to them, and which can be treated strictly as instruments" (Namkoong, 1991: 441) and, therefore, in the criteria to be used to divide subjects from objects. Another study that analyses the ethical aspect of biodiversity in a specific economic-productive context is Negri (2005). In particular, the paper examines the problems inherent to the biodiversity of agro-ecosystems with the aim of soliciting a reflection on the loss of agro-biodiversity due to profound changes in the socio-economic context. The ethical aspect of agro-biodiversity lies in the identification of any values that concern it; the 
identification of these values would justify the demands to safeguard agro-biodiversity and the definition of more effective policies and actions. The agro-food sector is a very studied field; in general the aim is to analyse the role (positive or negative) of the productions carried out in this sector with respect to biodiversity (e.g.: Engels, 2011; Le Coeur et al., 2002; Marshall \& Moonen, 2002; Paoletti, 2001; Tilman, 1999).

Finally, with reference to the more specific field of accounting, the analysis on biodiversity issue concerns, in particular, the problem of biodiversity assessment and its subsequent reporting. The studies will be disseminated starting in 2013 on the occasion of the first Special Issue of a high-level international magazine (AAAJ) on "Accounting for biodiversity" (Cuckston, 2013; Groom \& Freeman, 2013; Jones \& Solomon, 2013; Rimmel \& Jonäll, 2013; Siddiqui, 2013; Tregidga, 2013; van Liempd \& Busch, 2013). Subsequently, other studies, always included in a special Issue of the same scientific journal, propose reflections on new forms of ecology-centred accounting and reporting practices for biodiversity conservation and promotion (Adler et al., 2017; Cuckston, 2017; Feger \& Mermet, 2017; Ferreira, 2017; Gaia \& Jones, 2017; Laine \& Vinnari, 2017; Lanka et al., 2017; Russell et al., 2017; Sullivan \& Hannis, 2017). Except contribution of van Liempd \& Busch (2013), whose objective is to suggest that companies have ethical reasons to report on biodiversity issues, in these papers there is no prevailing ethical approach to biodiversity measurement.

In the light of the brief analysis of the literature, it is evident that the contributions in the business economic field are lacking; this can certainly represent a stimulus for further study.

\section{Ethical duties and economic behaviours}

Through the economic choices made by economic actors (companies, consumers, associations, institutions, etc.) it is possible, at least in part, to understand the current/future choices and perspectives on ethical-moral values. Through economic choices, economic actors define explicitly or implicitly, voluntarily or involuntarily, a personal ethical vision of their activity and their role within society and the environment. The economic system is therefore potentially able to show the system of ethical-moral values of this very subject. If the system of economic considerations and evaluations manages not to conflict, both conceptually and operationally, with the choices and aspects relating to environmental protection and conservation, an interesting and useful space opens up for virtuous ethical behaviour. Economic evaluations and considerations can be of help in defining a strategy of respect for the environment and its ethical aspects. This process does not only take place through national and/or international institutional choices, for example through taxes and sanctions that discourage negative behaviour, but also through the communicative aspect of economic choices, first and foremost through price, which becomes a signal and a reflecting mirror of what is being done, what is being bought/sold and the relative impacts. In this way the economic value system does not contrast the moral value system but becomes its supporter and facilitator. In the operational reality this positive collision 
and uniformity of intent does not represent normality: often the economic dimension is seen and considered separate or even adverse to the moral and environmental ethical dimension. It should also be noted that the economic aspect can have a negative effect on the respect of these principles; it is the case, for example, of too high prices that create a barrier to purchase for consumers and therefore a lack of opportunity to protect and promote environmental ethics.

The great difficulty in this process of rapprochement lies to a tendency not to consider, or to consider only partially, in economic choices, those of price but not only, the cost linked to the negative impact on the environment and in particular on biodiversity or the value (in the sense of protection, promotion and direct/indirect relative impacts on the environment) of a product or service that takes into account the ethical-moral principles of respect and protection of the natural environment. This difficulty may increase if the motivations and drives of the consumer are different from those of the producer/company. The personal ethical-philosophical conception of nature and its protection (including the protection of agricultural biodiversity), the local cultural context with its historical-religious traditions, the personal background of the two actors of the exchange (producer-consumer), have a considerable influence on the choices made in terms of ethical/economic value system. It is evident how the different philosophical conceptions related to the vision of nature and biodiversity described in the paragraph above give rise to different ethical drives and operational choices even very far apart from each other. Usually companies adopt in their vision and mission a well-defined perspective of how to conduct their core-business and other related activities, which should permeate the entire working environment, from the founder to the final product. On the market, however, this concept inevitably clashes with a reality characterized by rules, laws, customs and common traditions, but with a multitude of ways of seeing and facing reality.

\section{Methodology}

In the light of the above considerations, our aim is to understand how biodiversity is considered in the operational and economic reality operating in bakery industry, and, in particular, how it is considered from an ethical point of view. Since this is a conceptual paper that aims to understand the dynamics present in a particular and interesting industry (the natural and sustainable bakery) and since it is still a very little studied and deepened thematic area, it was decided to combine the theoretical treatment of the theme with the use of a Multiple Case Study (Yin, 2017). Through four exploratory case studies, the choice to investigate these issues in the bakery sector was taken for several reasons:

1) agro-biodiversity is a concept that is still not very deepened and considered (Lanka et al., 2017);

2) agro-biodiversity is the sub-category of biodiversity most at risk and most relevant for most of the European continent (Negri, 2005);

3) bread and its derivatives represent basic food products, purchased and consumed by almost 
all people in industrialized countries;

4) bakery industry is represented by a short supply chain, with only one intermediate step between the producer of the raw material (flour) and the consumer, i.e. the baker;

5) bakery industry is characterized by different needs, motivations, evaluations and ethical/moral, as well as philosophical considerations towards nature, of producers and consumers meet/conflict.

The area surveyed was selected for its vocation to produce bakery products, but more generally quality food products: Parma and Reggio Emilia (Emilia Romagna, Italy) form an area called Food-Valley, known and appreciated worldwide for food production. The exploratory case studies were conducted by the authors through the guidance of a specific Case Study Protocol that allowed to systematically and punctually investigate the subject matter of research in all the realities involved in the study. Through the inclusion also of a group of randomly selected consumers, for each bakery, it was possible to include in the analysis and discussion also the point of view of the final consumer, thus being able to compare this with the point of view of the producer. The four bakeries have been selected because they use biodiverse raw materials (in this case flours) that promote general agro-biodiversity and in particular the areas where the starting cereals are grown. They use mainly, but not exclusively, flours derived from grains of Italian origin belonging to landraces. These are non-genetically modified cereal varieties, typical of the area where they are cultivated and for this reason very resistant and less subject to treatment with chemical products. They are varieties that were in danger of disappearing because they were not used in favour of modern, genetically modified or selected and crossed cereals, with specific characteristics and better suited to intensive farming (Singh \& Abhilash, 2018; Thomas \& Kevan, 1993). The ancient grains used are: soft wheat Solina, Verna, Gentil Rosso, San Pastore, Virgo; durum wheat Perciasacchi, Saragolla, Russello; Einkorn wheat (Triticum monococcum). The four case studies are small companies, with a maximum of six employees and the active and constant presence of the owners. In this way, it was possible to have a good overall view of how these issues are considered and managed by both owners and staff. All bakeries studied have the point of sale directly adjacent and communicating with the production laboratory, in all cases totally or partially visible to the public. Most of the volume of sales is made in the point of sale of the headquarters, the remaining part takes place through organic supermarkets, farmers' markets, catering activities, solidarity buying groups. The activities are located in fairly central points in the cities (Parma and Reggio Emilia) and marked by a good or excellent passage of potential customers. In all bakeries, the type of product sold is clear, while the clarity on the type of raw material used and its specific characteristics varies. The item of communication and advertising is also very variable. These activities are contradicted by the production of bakery products with mother dough and local or national raw materials, mostly certified organic. These products are aesthetically different from those sold in traditional bakeries and also differ in the selling price (they have much higher prices). 
However, they are characterized by a higher digestibility, a higher presence of fibres, a longer duration, a clearer and more intense taste (Antognoni et al., 2017; Arzani \& Ashraf, 2017; Dinu et al., 2018). All the realities, apart from one that is now to be considered historical, are quite recent and have a modern and attractive sales method (furniture, counter positioning, product layout, etc.).

\section{Evidence discussion}

"Internal" vision: the bakers

A first important evidence collected during the multiple case study concerns the motivations with which these realities approach biodiversity management in their production and management operations. In all four cases, the companies are small, with the active presence of the owners. This first aspect tends to ensure consistency over time and uniformity of thought within the activity, in relation to the vision before that characterizes these realities. Being small realities of the territory it is clear that there is a strong link with the concept of local environment, local community and protection of the place where you live and work. This commitment begins, and is mainly characterized by the relationship with suppliers of raw material (flours). It is precisely in this relationship that the will to protect the environment can be implemented in practice and the principles of environmental ethics can be respected. The use by all the investigated realities of national organic flours, often produced at short or medium distance from the company headquarters, characterized by a production by small producers linked to the territory and the use of cereals of ancient varieties represents the first and main step towards an effective protection of agricultural biodiversity by producers. What is most interesting about this study is how these small producers arrive at the choice of this particular type of supplier and raw material: the ethical values that underlie these links.

Agricultural biodiversity is understood and considered with great attention by the realities investigated, even if with some difficulties. The very concept of biodiversity is immediately and without hesitation set against the concept of economy and money. It is perceived as something quite abstract, strongly linked to business ethics and moral values of respect for the environment and the planet on which we live, but as rather disconnected from reality and difficult to fully consider. Agricultural biodiversity is considered as a synonym of wealth, not in an economic-financial sense but in a human-natural sense.

\section{"Biodiversity is the opposite of flattening, it is richness."}

The recognition of this wealth, and its direct connection with environmental and human health, are the basis of the choice made with regard to the pursuit of a protection and promotion of nature itself in its entirety and fullness. The concept of wealth is also contemplated with reference to a "romantic vision" of nature and biodiversity that have shown two furnaces: nature 
and its wealth is seen and conceived as something beautiful and precious, in a sense that transcends the economic aspect and the daily operational reality. This romantic vision that is reconnected with the ecocentric conception of nature (romantic ecocentric approach) (Tomalin, 2009) represents a very subjective form of vision and approach to biodiversity and the natural world in which its aesthetic value is also considered.

"We have to consider it (agro-biodiversity) to be consistent with what we produce and do. It has a very high intrinsic value, we are the repositories of enormous richness. I am amazed by nature and I feel pain if we do not preserve it."

This aesthetic value, far from daily operations, seems to represent a sort of brake to the full consideration of the ethical-moral values connected in the company management of these ovens. If the use of a healthy and natural yeast, such as sourdough, and non-chemically treated, organic flours leads to an immediate consideration and recognition of the benefits for man and the environment, in the case of the use of biodiverse raw materials this recognition is less immediate, more impalpable, probably more filtered by the personal ethical vision and sensitivity of each individual person. The fact remains that nature and its biodiversity are seen as carriers of an intrinsic value, disconnected from any human, economic or other evaluation. The ecocentric vision of nature is predominant in the four case studies, the protection of biodiversity is seen as a mission, a necessity and an ethical-moral duty. In the totality of the realities investigated it became clear that the protection of biodiversity is linked to a greater well-being of nature and therefore indirectly or directly also of the human being. In the consideration of the raw materials to be used, in the type of products created and also in the way they are processed, nature and its respect are fully considered, in the knowledge that the output and outcome of what has been produced will have important positive effects. Nature and living beings, including man, are considered to be part of one big house, not divisible or not partially considered. This ethical conception of nature and biodiversity that distinguishes it belongs to three out of the four realities investigated.

"Nature is a whole. (...) The greater the biodiversity, the greater the well-being of the entire ecosystem. The protection and promotion of biodiversity is: a political act, an economic act, an environmental act, an agricultural act."

Two of these companies have an ecocentric basic concept but clearly reveal aspects that can be traced back to cosmocentrism and deep ecology.

One company considers nature and its wealth not as a simple complex of plant and animal living beings but as something that goes beyond what we know and understand today. The planet's ecosystem is conceived as an abstract living entity but with tangible effects on everyday reality. 
This ethical view of nature implies a deep respect for biodiversity, which is clearly recognized in different areas of life on earth and to which a crucial importance is recognized.

"We see the expressions of biodiversity. It's the only way for things to go well. Nature is our teacher."

Nature is recognised for its potential and skills that go beyond the classic human vision of the environment and its plant and animal inhabitants. The ecosystem is considered alive and perfect in its complexity and variety. The protection of this delicate balance for this bakery also depends on the choices made in its production activity, which is inextricably linked to the nature in which it is located. This conscious protection is seen as essential and obligatory, without which one would inexorably eliminate the foundations of life itself.

Linked to the vision described here is the conception of biodiversity and nature owned by the other company, which however reveals characteristics that can be traced back to the key principles of the Deep Ecology movement. This recognition of nature and its diversity as an indispensable and vital condition is shared, but there is also a conceptual and practical attempt to resolve current problems, in a more operational and even more pessimistic vision. More drastic solutions and the recognition of a too sharp fracture in society between human beings and nature are at the basis of this bakery's approach. It is precisely the awareness of a clear divide between the modern human being and the natural environment that drives this company to consider alternatives and solutions oriented towards a more rigid and integral ecology.

"Man must destroy himself before he can evolve. We've reached an extreme point."

The last bakery, which cannot be traced back to an ecocentric approach to the relationship between ethics and biodiversity, adopts a vision oriented towards anthropocentrism. Nature and biodiversity are considered relevant, even if they are treated as something rather abstract and intangible, but for a human purpose, whether in health or economics. Agricultural biodiversity is considered and well known but changes the basic motivation for this consideration and the direct and indirect effects it expects to have or wants to achieve through this protection. The use of raw materials that protect and promote biodiversity is designed to produce a different, more attractive, healthier product that brings a positive economic return. In this case there is a lack of awareness or willingness to have a positive effect on the natural ecosystem, its wealth. The ethical-moral values in this case, although present, are not at the basis of the economicmanagerial choices adopted by the company, but are relegated to a possible motivation for consumers and therefore an economic-commercial tool.

\section{Meeting the "External" vision: the consumers}

This use of ethical-moral principles as a commercial tool finds fertile ground in the consumers 
and buyers of these four investigated realities. They are a category of consumers on average more informed and aware of the characteristics of the product purchased, but rarely more aware of the impacts of that product on the environment and its biodiversity. The anthropocentric conception is detectable in the vast majority of consumers affected by this study. What stands out most from the analysis of the data collected in the case studies is the main basic motivation with which consumers choose to purchase this particular type of product. Personal health is almost always the driving force that brings these people closer to these products and businesses. The concept of protection and protection of the environment and biodiversity and therefore of respect for ethical-moral principles towards nature are often completely absent in this actor of commercial exchange, except for some for whom it represents a secondary and little rooted presence and for others, the minority, for whom it represents the main motivation. It is clear how this difference in motivations and basic conceptions between the two main players in this market can create friction and difficulties. On the one hand, there are consumers who are unable to understand certain choices regarding the raw materials used, the types of product created, the prices charged, and the methods of sale and distribution. On the other hand there are producers who arrive at the last and fundamental step having to surrender or adapt to logics and ethical visions completely different from those that have pushed them to do what they do and to do it as they do it. These mutual difficulties in some cases have led or risk leading to either a consumer giving up or a change on the part of the producer. The difficulties just described have as a direct consequence a reduced effectiveness of the farm practices of these producers towards a real and efficient protection and promotion of agricultural biodiversity.

\section{Conclusion}

The relationship between ethics and biodiversity is complex and involves different philosophical approaches ranging from anthropocentrism to cosmocentrism. With reference to a specific agro-food sector (Bakery) this study has allowed to place the positions and choices of some entrepreneurs in the different ethical approaches to nature and therefore to biodiversity. It was also possible to highlight how the different behaviours of consumers and producers arise from the ethical conceptions through which they look at reality and the consequences of their choices and their production and sales activities. These are profound visions and motivations that determine extremely different operational behaviours and impact on our reality. A contribution to the academic and business community through this study is precisely to identifying, through an in-depth analysis of multiple case studies, the real motivations behind certain behaviours and what are the consequent determinants of the problems that exist today in this type of market. An important work of sensitization and divulgation of the effects on nature and its wealth through simple purchase/sale operations is desirable to try to make the majority of consumers understand the motivations of the choices adopted and applied by producers. Secondly, to avoid negative and non-productive collisions between two market 
players operating with different visions. If the change in the basic ethical conception of a person or group of people towards nature and the environment is extremely complex and perhaps not even desirable, a new and ever-present consideration of the natural aspects and the possible consequences of our actions, even the simplest ones such as buying a loaf of bread, on the whole ecosystem could be of extreme importance. Like all scientific work, this contribution has some limitations: the main ones are to consider a particular industry (the natural and sustainable bread-making), and a limited geographical area (the Italian Food Valley). Future research may pose the same questions as research in other geographical areas or other market sectors. It will also be very interesting to understand, through further studies, how some specific economic disciplines, for example marketing, management, accounting, can provide solutions or tools to overcome areas of friction between market players and to try to reconcile at least in part the motivations or practical objectives towards a common and participatory concrete attention to nature and its biodiversity.

\section{References}

Adler R., Mansi M., Pandey R. \& Stringer C. (2017). United Nations Decade on Biodiversity: A study of the reporting practices of the Australian mining industry. Accounting, Auditing \& Accountability Journal, 30(8): 1711-1745.

Antognoni F., Mandrioli R., Bordoni A., Di Nunzio M., Viadel B., Gallego E., Villalba M.P., Tomás-Cobos L., Taneyo Saa D.L., \& Gianotti A. (2017). Integrated Evaluation of the Potential Health Benefits of Einkorn-Based Breads. Nutrients, 9(11): 1232.

Arzani A., \& Ashraf M. (2017). Cultivated Ancient Wheats (Triticum spp.): A Potential Source of Health-Beneficial Food Products. Comprehensive Reviews in Food Science and Food Safety, 16(3): 477-488.

Brian G.N. (1984). Environmental Ethics and Weak Anthropocentrism. Environmental Ethics, 6(2): 131-148.

Butkus M. (2015). All Health is Local: Biodiversity, Ethics, and Human Health. Ethics, Policy \& Environment, 18(1): 1-15.

Callicott J.B. (2002). The Pragmatic Power and Promise of Theoretical and Environmental Ethics: Forging a New Discourse. Environmental Values, 11: 3-25.

Cuckston T. (2013). Bringing tropical forest biodiversity conservation into financial accounting calculation. Accounting, Auditing \& Accountability Journal, 26(5): 688-714.

Cuckston T. (2017). Ecology-centred accounting for biodiversity in the production of a blanket bog. Accounting, Auditing \& Accountability Journal, 30(7): 1537-1567.

des Jardins J.R. (1997). Environmental ethics. Second edition. London: Wadsworth.

Devall B. \& Sessions G. (1985). Deep ecology. Layton (Utah): Gibbs M. Smith, Inc.

Dinu M., Whittaker A., Pagliai G., Benedettelli S., \& Sofi F. (2018). Ancient wheat species and human health: Biochemical and clinical implications. The Journal of Nutritional Biochemistry, 52: 1-9.

Engels J.M.M., Dempewolf H. \& Henson-Apollonio V. (2011). Ethical Considerations in Agrobiodiversity Research, Collecting, and Use. Journal of Agricultural Environmental Ethics, 
24:107-126.

Feger C. \& Mermet L. (2017). A blueprint towards accounting for the management of ecosystems. Accounting, Auditing \& Accountability Journal, 30(7): 1511-1536.

Ferreira C. (2017). The contested instruments of a new governance regime: Accounting for nature and building markets for biodiversity offsets. Accounting, Auditing \& Accountability Journal, 30(7): 1568-1590.

Gaia S. \& John J.M. (2017). UK local councils reporting of biodiversity values: A stakeholder perspective. Accounting, Auditing \& Accountability Journal, 30(7): 1614-1638.

Groom B. \& Freeman M.C. (2013). Biodiversity valuation and the discount rate problem. Accounting, Auditing \& Accountability Journal, 26(5): 715-745.

Hamilton L.R. (ed.) (1993). Ethics, Religion, and Biodiversity: Relations between Conservation and Cultural Values. Cambridge (UK): The White Horse Press.

Jenkins W. (2003). Biodiversity and Salvation: Thomistic Roots for Environmental Ethics. The Journal of Religion, 83(3): 401-420.

Jones M.J. \& Solomon J.F. (2013). Problematising accounting for biodiversity. Accounting, Auditing \& Accountability Journal, 26(5): 668-687.

Kant I. (1963). Duties to Animals and Spirits. Harper Row: New York.

Laine M. \& Vinnari E. (2017). The transformative potential of counter accounts: A case study of animal rights activism. Accounting, Auditing \& Accountability Journal, 30(7): 14811510 .

Lanka S.V., Khadaroo I. \& Böhm S. (2017). Agroecology accounting: Biodiversity and sustainable livelihoods from the margins. Accounting, Auditing \& Accountability Journal, 30(7): 1592-1613.

Le Coeur D., Baudry J., Burel F. \& Thenail C. (2002). Why and How We Should Study Field Boundary Biodiversity in an Agrarian Landscape. Agriculture, Ecosystem and Environment, 89: 23-40.

Leopold A. (1949). A sand county almanac and sketches here and there. Oxford: Oxford University Press.

Marshall E.J.P. \& Moonen A.C. (2002). Field Margins in Northern Europe: Their Functions and Interactions with Agriculture. Agriculture, Ecosystem and Environment, 89: 5-21.

Mathews F. (2016). From biodiversity-based conservation to an ethic of bio-proportionality. Biological Conservation 200: 140-148.

McEwan C., Hughes A. \& Bek D. (2014). Futures, ethics and the politics of expectation in biodiversity conservation: A case study of South African sustainable wildflower harvesting. Geoforum, 52: 206-215.

Minteer B.A. \& Collins J.P. (2005). Ecological Ethics: Building a New Tool Kit for Ecologists and Biodiversity Managers. Conservation Biology, 1803-1812.

Naess A. (1973). The shallow and the deep, long-range ecology movement. A summary. Inquiry, 16(1-4): 95-100.

Namkoong G. (1991). Biodiversity - Issues in genetics, forestry and ethics. The Forestry Chronicle, 68 (4): 438-443.

Negri V. (2005). Agro-biodiversity conservation in Europe: Ethical issues. Journal of 
Agricultural and Environmental Ethics, 18: 3-25.

Nelson M.P. (2002). "Introduction to Environmental Ethics", in The Biodiversity Project (eds.) Ethics for a Small Plane: A Communications Handbook on the Ethical and Theological Reasons for Protecting Biodiversity, The University of Wisconsin Press, pp. 41-47.

Norton B.G. (1984). Environmental ethics and weak anthropocentrism. Environmental Ethics, 6: 131-148.

Norton B.G. (2000). Biodiversity and Environmental Values: In Search of a Universal Earth Ethic. Biodiversity and Conservation, 9: 1029-1044.

Paoletti, M. (2001). "Biodiversity in Agroecosystems and Bioindicators of Environmental Health", in Shiyomi M. \& Koizumi H. (eds.), Structure and Function in Agroecosystems Design and Management. Advances in Agroecology. Boca Raton (FL): CRC Press, pp. 1144.

Rimmel G. \& Jonäll K. (2013). Biodiversity reporting in Sweden: Corporate disclosure and preparers' views. Accounting, Auditing \& Accountability Journal, 26(5): 746-778.

Rolston H. III (1988). Environmental ethics: duties to and values in the natural world. Pennsylvania: Temple University Press, Philadelphia.

Rolston H. III (1994). "Value in Nature and the Nature of Value", in Attfield R. \& Belsey A. (eds.), Philosophy and the Natural Environment, Royal Institute of Philosophy Suppl. 36. Cambridge: Cambridge University Press, pp. 13-30.

Russell S., Milne M.J. \& Dey C. (2017). Accounts of nature and the nature of accounts. Accounting, Auditing \& Accountability Journal, 30(7): 1426-1458.

Russow L-M. (2002). "Environment. Case Study: Marie the Envinronmentalist", in Comstock G. (ed.), Life Science Ethics, Ames (IA): Iowa State Press, pp. 93-123.

Schweitzer A. (1923). Civilization and Ethics. London: A. \& C. Black.

Siddiqui J. (2013). Mainstreaming biodiversity accounting: Potential implications for a developing economy. Accounting, Auditing \& Accountability Journal, 26(5): 779-80.

Singh A., \& Abhilash P.C. (2018). Agricultural biodiversity for sustainable food production. Journal of Cleaner Production, 172: 1368-1369.

Spash C.L., Urama K., Burton R., Kenyon W., Shannon P. \& Hill G. (2009). Motives behind willingness to pay for improving biodiversity in a water ecosystem: Economics, ethics and social psychology. Ecological Economics, 68: 955-964.

Sullivan S. \& Hannis M. (2017). "Mathematics maybe, but not money.” Accounting, Auditing \& Accountability Journal, 30(7): 1459-1480.

Taylor P.W. (1981). The Ethics of Respect for Nature. Environmental Ethics, 3: 197-218.

Taylor P.W. (1986). Respect for Nature: A Theory of Environmental Ethics. Princeton (NJ): Princeton University Press.

Thomas, V. G., \& Kevan, P. G. (1993). Basic principles of agroecology and sustainable agriculture. Journal of Agricultural and Environmental Ethics, 6(1), 1-19. https://doi.org/10/crzprc

Tilman D. (1999). Global Environmental Impacts of Agricultural Expansion: The Need for Sustainable and Efficient Practices. Proceeding of the National Academy of Science, 96: 5995-6000. 
Tilman D. (2000). Causes, Consequences and Ethics of Biodiversity. Nature, 405: 208-211.

Tobias M. (ed.) (1985). Deep ecology. An anthology. San Diego: Avant Books.

Tregidga H. (2013). Biodiversity offsetting: Problematisation of an emerging governance regime. Accounting, Auditing \& Accountability Journal, 26(5): 806-832.

UNESCO (2011). Ethics and Biodiversity. Ethics and Climate Change in Asia and the Pacific (ECCAP) Project, Working Group 16 Report. UNESCO Bangkok - Regional Unit for Social and Human Sciences in Asia and the Pacific.

van Liempd, D. \& Busch J. (2013). Biodiversity reporting in Denmark. Accounting, Auditing \& Accountability Journal, 26(5): 833-872.

Yin R.K. (2017). Case Study Research and Applications: Design and Methods (Sixth edition). SAGE Publications, Inc. 